This is the first of three articles in a series by Dr. Lee. The second will appear in the Summer issue and the third will be published in the Fall issue.

JAMES L. LEE Ph.D. / University of Michigan

\title{
TOWARD A MODEL OF VOCATIONAL PERSISTENCE AMONG SEMINARIANS: PART 1
}

Those working in seminary training have long suspected that the personal characteristics of dropouts differ from those who remain in or complete the training program. Knoweles (1958) stated that the literature reveals a growing concern for qualitative analysis of the characteristics of religious students; and among the important areas of needed research suggested by McCarthy (1960) are studies dealing with the differences between those who remain in and those who leave seminary training.

Past research (Kennedy, 1958; Sweeney, 1964; Vaughan, 1963; etc.) has found individual variables which significantly differentiate between staying in and leaving seminary training. The statistics have not been accurate enough for individual prediction and the results of other studies using the same variables on different populations have been inconclusive enough to produce the general conclusion that the majority of those who leave the seminary do so, not because of unsuitability, but because of insufficient motivation (D'Arcy and Kennedy, 1965). To the author's knowledge there have been few investigations aimed at determining the motivations of seminary persisters and leavers.

The primary interest in the study of motivation "...is to identify and understand the effects of all the important contemporaneous influences which determine the direction of action, its vigor, and its persistence" (Atkinson, 1966, p. 2). Lewin (Atkinson, 1966) 
offers the following model, among others, which, if generalized, may help to identify the contemporaneous influences of motivation among seminarians, $B=f(P E)$, (i.e., behavior is an interrelated function of the person and his psychological environment). The motivation of an individual in applying for and perservering in training for the priesthood is a function of the person himself (his characteristics, abilities, interests, etc.) and the environment (seminary, priesthood, and the Church) as he perceives it. If motivation is interpreted according to the concepts of Atkinson and Lewin, then those who leave the seminary prior to completion do not possess insufficient motivation, rather, their motivation may be different from those who continue in or complete the program. If those who leave have different motivation, it should then be possible to measure the differences in some manner.

The results presented here are part of an investigation to explore as exhaustively as is presently possible the motivational pinenomenon of certain students who persist in the seminary as compared with students who voluntarily leave. This investigation does not serve the usual function of theory and model testing, rather, the in-depth exploration of data may provide a basis for religious vocational development and maintenance theory and indicate specific areas for future empirical research through the offering of some tentatively proposed hypotheses.

\section{PROCEDURES}

The first approach in this exploratory examination was to determine through the traditional statistical analyses whether there were any individual variables or combination of variables in a stepwise regression equation which significantly differentiated between a group of seminarians and a group of ex-seminarians or significantly predicted persisting or leaving.

The second approach was to investigate, in an exploratory manner, sub-groups or "types" of seminarians and ex-seminarians based on the tested characteristics used in this investigation. An exploratory cluster computer program was used to identify clusters of individuals within the sample of seminarians and ex-seminarians. While the clusters are formed by the computer, the formation of clusters is specified by the types and amounts of data used for each individual. Forty two test variables from the $16 \mathrm{PF}, \mathrm{Kuder}$ Preference Record, Vocational, Form CH, California Test of Mental Maturity, Differential Aptitude Test, National Merit Scholarship Qualifying Test, and the Scholastic Aptitude Test were used. All 42 test variables were used simultaneously to form the clusters.

\section{POPULATION}

If the results of an exploratory analysis suclı as this is to be useful as a basis for theory and model building, it is imperative to examine the population in some detail as compared with other sample populations which have been studied in the past or may be 
studied in the future. The sample population was from the minor seminary, Sacred Heart Seminary, Detroit, Michigan. The total sample consisted of those individuals with complete data from the three high school graduation classes of 1965, 1966, and 1967. Because of the computer programs used within the entire study, the final total experimental sample consisted of 60 seminarians and 60 ex-seminarians.

The subjects in this investigation appeared to be quite similar to other seminarian and ex-seminarian groups studied by other researchers (Fichter, 1961; Mateo, 1964; Foley, 1965; Lonsway, 1968). As indicated in Table I, the subjects in this study come from a middle or high income social background. Their mothers and fathers were living and their mothers play the part of housewife and "mother" rather than that of an additional breadwinner. There were an average or above average number of children in the family, of which they were the first or second born. A large percentage of them had a relative in the religious life-priest, nun, or other seminarian. While attending a Catholic parochial grade school, they were altar boys. They were influenced in their decision to enter the seminary more by religious than by their parents. Finally, as might be expected of boys at age fourteen, their early vocational preferences were varied.

\section{RESULTS}

After ascertaining the nature and comparability of the sample with others which have been investigated, the total experimental sample was divided into the respective sub-groups of persisters and leavers. Analysis of variance and regression analysis computer programs were used to identify those of the 42 test variables which significantly discriminated between the two groups or significantly predicted persisting or leaving. Table II presents the significant results of the analysis of variance and Table III presents the significant steps of the regression equation.

There were no aptitude and achievement variables which individually differentiated between the two groups, suggesting, as D'Arcy and Kennedy, that the leavers are not unsuitable at least in their ability to accomplish the academic requirements of the seminary. Some significant differences do exist between the two groups. Those who persist are, as a group, significantly more submissive and have significantly higher musical and social interests than do those who leave. On the other hand, those who leave are, as a group, significantly higher in scientific and literary interests than are those who persist. Through the addition of the I.Q., clerical interest, mechanical reasoning, and self-esteem scores to the others mentioned above, a multiple correlation coefficient of .586 was derived in a regression equation that significantly predicts persisting in or leaving seminary training.

These data coincide quite closely with those obtained by others in studying seminary groups. McCarthy (1960) mentions that there' is strong evidence to suggest that 
seminarians are more submissive than ex-seminarians. D'Arcy (1962) indicates that seminarian groups are uniformily high on the Kuder social and musical scales as compared with those who leave seminary training. However, as has been found by others (Friedl, 1952; Kenny, 1959; Morse, 1962; etc.), although there are significant differences between the two groups, the accuracy of the statistics is not great enough for individual prediction because of the wide within-sample variations indicated by the standard deviations and the percent of variance left unaccounted for in the regression equation. These data do support the following hypotheses:

Seminarians who are submissive in their social relations are more likely to remain in seminary training than those who are assertive.

Those who persist in seminary training have, as a group, higher manifest social and musical interests than do those who leave.

Those who leave seminary training have, as a group, higher manifest literary and scientific interest than do those who persist.

The exploratory cluster program was used with the 42 test variables to identify within sample sub-groups of individuals as a basis for further understanding seminary persisters and leavers. The cluster analysis process gradually associates groups of individuals whose members have mutually high similarity coefficients (a correlation coefficient between pairs of individuals using all input data). The analysis of variance is then used to determine those individual variables which significantly differentiate the clusters. This computer program is limited to 99 individuals or variables to be clustered at one time because of the storage capacity of the computer. Accordingly, a random sample of 45 persisters and 45 leavers were used for the cluster analysis. The persisters and leavers were clustered together because it was reasoned that the degree of mixture of persisters and leavers in the generated clusters would identify those from the two groups who were most similar. Further, the generation of clusters which were composed entirely of leavers or entirely of persisters and clusters in which the majority were either persisters or leavers would identify specific sub-groups which might provide another way of viewing the phenomenon of remaining in or leaving seminary training. It should be remembered that...

The clusters produced by the computer represent new, rather than previously contrived constellations, and cannot be assumed to have either theoretical or practical significance. The clusters should be viewed chiefly as a starting point for furtler investigation (Johnson, 1967, p. 1).

Tables IV, V, and VI present the mean scores of the clusters on each of the scales. The data for each cluster is presented in three different tables only as a matter of convenience and it should be remembered that the clusters were formed by using all 42 test variables simultaneously. The results from the cluster analysis will be discussed in relation to the 
hypotheses which they seem to suggest. These hypotheses are tentative in nature and will require furtner investigation even though they are based upon the present data.

The majority of those who leave the seminary training do not differ essentially from the majority of those who persist on personality, interest, and aptitude measures.

An examination of the largest cluster generated by the computer (cluster 1) indicates that it is comprised of 30 persisters and 24 leavers. The combination of almost equal numbers of both groups within the largest cluster generated suggests that there are no major differences between the majority of those who persist and the majority of those who leave, at least on the objective measures used in this investigation. This coincides with the results of the analysis of variance between the two groups of persisters and leavers in which the standard deviations were found to be wide enough to indicate that there was a great deal of over-laping between the groups on the various measures. Distinct sub-groups do exist as indicated in the tables. These smaller sub-groups are interpreted as representing the extremes within the sample population which were responsible for the significant differentiation found in the analysis of variance. Past research attempting to differentiate between seminarians and ex-seminarians has obtained similar results. Although Bier (1956), Gorman, (1961), and McDonagh (1961), among others, have been able to obtain significant differentiation with personality measures and Lhota, (1948), Joseph, (1959), and Maffia, (1964) have been able develop interest scales that differentiate between groups of seminarians as compared with ex-seminarians and lay groups, the statistics have not been accurate enough for individual prediction. Such findings as these also suggest that the majority of individuals within the samples are quite similar, even though there are individuals who deveiate far enough from the means to produce statistically significant differentiation between the groups.

\footnotetext{
Those seminarians who exhibit subjective personality and interest profiles are more likely to remain in seminary training.

Those seminarians who exhibit objective personality and interest profiles are more likely to leave seminary training.
}

The more subjectively oriented individual is more open to his feelings and emotions, preferring to operate on an affective rather than an intellectual level. He is characterized by adjectives such as warm, open, soft, and empathetic. His 16PF profile is sociable, submissive, sensitive, trusting, artless, strong social conscience (super ego), group dependent, and he has a tendency to be anxious and tense. His interest profile centers in the social, musical, literary, and artistic areas. This individual's general orientation is, therefore, toward people rather than things. These profiles characterize the persisters in cluster 1 and 5 . 
The more objectively oriented individual prefers to operate on an intellectual rather than an affective level. He is characterized by adjectives such as hard, stern, competitive, and achieving. His 16PF profile is aloof, assertive, and independent, realistic, suspicious, shrewd, self-sufficient, and he meets anxieties in a well-ordered and controlled manner. His interest profile centers in the mechanical, computational, scientific, and clerical areas. This individual's general orientation is, therefore, toward things rather than people. These profiles characterize the leavers especially in clusters 2 and 4 and to a certain extent those in cluster 3 .

The more creative the seminarian's personality and interest profile the more likely he will leave the seminary training.

The one cluster of persisters (no. 5) obtained a creativity score of 7.0 which is one and a half standard deviations above the mean of 5.5 and is indicative of creative personalities as measured by the eleven scales of the $16 \mathrm{PF}$ which comprise this scale. In contrast, two of the clusters which contain a majority of leavers both obtain creativity scores of 7.0 . It is difficult to relate the creativity research to seminarians because the research indicates that, while there is some commonality in personality characteristics among creative individuals, there are also wide differences between occupations and professions. Therefore, while creative mathematicians, architects, researchers, etc. exhibit some common characteristics, there are between group variations. Creative seminarians cannot be directly compared to any other profession, but those characteristics which seem to be common to all professions are relevant to this discussion.

A summary description of the common characteristics of creative individuals as they are revealed on the $16 \mathrm{PF}$ reads as follows:

The creative person is aloof, tending to be critical and suspicious in his thinking. He has at least average intelligence and is introspective and sensitive. He is also imaginative and disposed toward experimentation in problem solving.

$\mathrm{He}$ is dominant, assertive, and independent in his behavior. He is self-sufficient, self-confident, and self-assured, and relates to others in an unaffected, spontaneous, friendly manner.

The description of the creative individual from the 16PF scales indicates that there is a precarious balance between the objective and subjective traits and interests within the individual. The creative person is dominant, self-confident, and independent but also relates to others in an unaffected, spontaneous, and friendly manner. He is aloof and introspective but is also sensitive. The creative seminarians in this study have interest profiles which further suggest this precarious balance between the subjective and objective aspects of their personalities. They exhibit strong patterns of interest in the 
subjective areas-social, literary, musical, or artistic-as well as strong interest patterns in the objective areas-mechanical, computational, scientific, or clerical. Cluster 2 which has a majority of leavers obtained a creativity score of 7.0 and has strong interests peaks on the sucial, literary, and scientific scales. Cluster 4 aiso obtained a high creativity score and has strong interest peaks on the social, artistic, computational, scientific, and clerical scales.

The more creative seminarian may not always be to the liking of the authorities or teachers. This will be due to his independence in thought or behavior in situations in which non-conformity may seriously disrupt the general order of the seminary system. In struggling to reconcile the strong opposites in his nature and striving to achieve creative solutions to difficult problems, he will express views and behave in a manner which is contrary to what is usually expected of the "normal" seminarian.

\section{SUMMARY}

We have examined the concept of motivation as it might apply to the seminarian and his persistence in seminary training. The general conclusion that those who leave the seminary have insufficient motivation appears to be unsatisfactory both as a final product of former research and as a basis for future investigation. In the present article we have examined quite exhaustively the personal characteristics of a group of seminarians and ex-seminarians through the use of some of the more traditional statistical techniques and an exploratory process which has allowed us to examine the group in some detail. Most of the data and hypothese generated from these two approaches are neither startling nor new but do provide significant normative data as a basis for seminary development and the establishment of general seminary admission policies. On the other hand, the further investigation of creativity among seminarians would appear to hold some promise. To this point this research and that of many others has concentrated on the seminarian's personality, aptitude, and interest or his biographical and demographical characteristics as separate entities. It remains to examine in some detail his "psychological environment" and its interface and interaction with his personal characteristics.

\section{REFERENCES:}

Atkinson, J.W. An Introduction to Motivation. New York: D. Van Nostrand, 1966.

Bier, W.C. A comparative study of five Catholic college groups on the MMPI. In G.S. Welsh \& W.G. Dohlstrom (Eds.), Basic Readings on the MMPI in psychology and medicine. Minneapolis: Univ. of Minnesota Press, 1956, 586-609.

D'Arcy, P.F. Constancy of interest factor patterns within the specific vocation of foreign missionary. Stud. in Psychol. \& Psychiat., 1954, 9, 1, 54.

D'Arcy, P.F. \& Kennedy, E.C. The Genius of the Apostolate. New York: Sheed \& Ward, 1965.

Fichter, J.H., S.J. Religion as an Occupation, Notre Dame, Ind.: Univ. of Notre Dame Press, 1961. 
Foley, E.C. A study of some socio-religious factors in the home backgrounds of a vocational family group and a non-vocational family group. In R.J. Menges \& J.E. Dittes (Eds.), Psychological studies of clergymen: Abstracts of research. New York: T. Nelson, 1965 (Abstract).

Friedl, F.P. Vocational interests of successful and unsuccessful seminarians in foreign mission society. M.A. Thesis, Cath. Univ. of Am., 1952.

Gorman, J.R. Adjustment and interests of fourth year minor seminarians studying for the diocesan priesthood. In R.J. Menges \& J.E. Dittes (Eds.), Psychological studies of clergymen: abstracts of research. New York: T. Nelson, 1965 (Abstract).

Johnson, M.C. A Computer program to develop clusters of individuals or variables. Unpublished Mimeographed Paper. Ann Arbor: Univ. of Michigan, 1967.

Joseph, M. A Kuder-D key for young male religious teachers. Cath. Couns., 1959, 4, 10, 17-22.

Kennedy, E.C. A comparison of the psychological test scores of successful and unsuccessful major seminarians in a foreign mission seminary. M.A. Thesis, Cath. Univ. of Am., 1958.

Kenney, C.E. Differential vocational interest patterns of successful and unsuccessful foreign mission seminarians. Unpublished doctoral dissertation, Loyola Univ. (Chicago), 1959, Dissert. Abstract., 1959.

Knoweles, R.G. Differential characteristics of successful and unsuccessful seminary students. Unpublished doctoral dissertation, University of Nebraska, 1958, Dissert. Abstract., 1958.

Lee, James L. An exploratory search for characteristic patterns and clusters of seminary persisters and leavers. Unpublished doctoral dissertation, Univ. of Michigan, 1968.

Lhota, B. Vocational interests of Catholic priests. Stud. in Psychol \& Psychiat., 1948, 7 , 1.

Lonsway, F.A. Background characteristics and goals of Catholic theological students. NCGC Journal, 1968, 12, 2, 101-118.

McCarthy, T.N. Psychological assessment and the religious vocation. Cath. Couns., 1960, 4, 2, 44-49.

McDonagh, A.J. A study of adjustments and interests of first year college seminarians for the diocesan priesthood. In R.J. Menges \& J.E. Dittes (Eds.), Psychological studies of clergymen: abstracts of research. New York: T. Nelson, 1965 (Abstract).

Maffia, L.A. Measured interests of priests, seminarians, and former seminarians in the selection of seminary applicants. In R.J. Menges \& J.E. Dittes (Eds.), Psychological studies of clergymen: abstracts of research. New York: T. Nelson, 1965 (Abstract).

Mateo, L.G. A study of the problems of the third, fourth, and fifth year minor seminarians in the diocesan seminaries in the Philippines. Unpublished doctoral dissertation, Fordham Univ., 1964, Dissert. Abstract., 1964.

Morse, P.K. The Strong Vocational Interest Blank and Minnesota Multiphasic Personality Inventory as measures of persistence toward the ministry as a vocational goal. Unpublished doctoral dissertation, Univ. of Michigan, 1962.

Sweeny, R.H., C.S.C. The morality of psychological testing of vocational prospects. Natl. Cath. Educ. Ass. Bull., 1964, 61, 1, 374-379.

Vaughan, R.P. A psychological assessment program for candidates to the religious life. Cath. Psychol. Rec., 1963, 1, 65-70. 


\section{TABLE I}

Total Numbers and Percentages of Persisters, Leavers and the Entire Sample Possessing Individual Biographic and Demographic Variables

Variables

Father Living

Mother Living

Altar Boy in grade school

Attended parochial grade school

Father's Occupational Level

Unskilled, semi-skilled

Skilled, Mang., Sales

Professional \& Self-emp.

Mother's Occupational Level

Unskilled, semi-skilled, housewife $56 \quad 94$

Skilled, Mang., Sales

Professional \& Self-emp.

Father's Educational Level

Less than high school

High school graduate

College and/or Graduate

Mother's Educational Level

Less than high school

High school graduate

College and/or graduate

Number of Children in family

one

two

Three or more

Ordinal Position in family

First born

Second born

Third born or below

Relative in the religious life

Priest or Nun

other seminarian

Most influential in helping to make decision to enter seminary

Religious/priest or nun

Persisters
N \%

$59 \quad 99$

60100

$56 \quad 92$

$58 \quad 97$

$6 \quad 10$

$39 \quad 65$

$15 \quad 25$

203

203

$15 \quad 25$

$23 \quad 38$

$22 \quad 37$

$12 \quad 20$

$38 \quad 68$

$10 \quad 12$

610

$23 \quad 38$

$31 \quad 52$

$34 \quad 57$

1220

$14 \quad 23$

$37 \quad 62$

$12 \quad 20$

$\begin{array}{ll}7 & 12\end{array}$

34

57
Leavers

$\mathrm{N} \%$

$60 \quad 100$

$58 \quad 97$

$55 \quad 91$

$59 \quad 99$

$11 \quad 18$

$37 \quad 62$

$12 \quad 20$

$56 \quad 94$

305

101

$10 \quad 18$

$22 \quad 36$

$28 \quad 46$

$\begin{array}{ll}8 & 18\end{array}$

$42 \quad 70$

$10 \quad 12$

$17 \quad 15$

$\begin{array}{ll}76 & 62\end{array}$

$27 \quad 23$

11294

504

302

$25 \quad 21$

$\begin{array}{ll}55 & 37\end{array}$

$50 \quad 42$

$20 \quad 15$

$80 \quad 70$

$20 \quad 15$

1308

$50 \quad 42$

$57 \quad 50$
$54 \quad 54$

$29 \quad 24$

$27 \quad 22$

$70 \quad 59$

$29 \quad 24$

$12 \quad 10$ 
Parents

Other

Early Vocational Preferences

Helping

Non-helping

None

$\begin{array}{rr}8 & 13 \\ 18 & 30\end{array}$

$\begin{array}{ll}31 & 52\end{array}$

$23 \quad 38$

$\begin{array}{ll}6 & 10\end{array}$ $\begin{array}{ll}12 & 18\end{array}$

$\begin{array}{ll}16 & 27\end{array}$

$20 \quad 15$

$46 \quad 30$

$\begin{array}{ll}56 & 47\end{array}$

$\begin{array}{ll}48 & 40\end{array}$

$16 \quad 13$

\section{TABLE II}

\section{Significant Analysis of Variance Results}

\begin{tabular}{lccccc} 
& \multicolumn{2}{c}{ Persisters } & \multicolumn{2}{c}{ Leavers } & \\
\multicolumn{1}{c}{ Variables } & Mean & S.D. & Mean & S.D. & $\mathrm{t}$ Test \\
Dominance vs. Submission & 4.4 & 2.2 & 5.6 & 2.1 & $2.83^{* *}$ \\
Scientific Interest & 34 & 28.5 & 47.5 & 31.3 & $2.47^{*}$ \\
Literary Interest & 60.6 & 31.6 & 72.3 & 26.1 & $2.21^{*}$ \\
Musical Interest & 53.4 & 26.4 & 42.4 & 26.1 & $2.31^{*}$ \\
Social Interest & 88.5 & 15.9 & 74.9 & 27.8 & $3.28^{* *}$ \\
& & & & & \\
$* \mathrm{t}=1.96$ is significant at the .05 level & & & & \\
$* * \mathrm{t}=2.58$ is significant at the .01 level & & & &
\end{tabular}

TABLE III

Significant steps of the Multiple Regression Analysis Predicting Persisting in or Leaving Seminary Training

$\begin{array}{llll}\text { Steps } \quad \text { Variable Entering } & \mathrm{MR} & \mathrm{R}^{2} & \mathrm{~F} \text { Level } \\ \text { 1. Social Interest } & .289 & .084 & 10.79^{* *} \\ \text { 2. Scale E-16PF Dominance } & .371 & .138 & 7.41^{* *} \\ \text { 3. Musical Interest } & .424 & .179 & 5.89^{*} \\ \text { 4. Literary Interest } & .476 & .227 & 6.98^{* *} \\ \text { 5. Clerical Interest } & .506 & .257 & 4.61^{*} \\ \text { 6. CTMM - I.Q. } & .535 & .287 & 4.69^{*} \\ \text { 7. Scale Q3-16PF Self-Esteem } & .556 & .309 & 3.62 \\ \text { 8. DAT Mechanical Reasoning } & .586 & .343 & 5.84^{*} \\ & & & \\ \text { MR = Multiple Correlation } & { }^{*} \mathrm{~F}=3.9 \text { is significant at the } .05 \text { level } \\ \text { R2 }=\text { Percent of Variance } & { }^{* *}=6.8 \text { is significant at the .01 level }\end{array}$




\section{TABLE IV}

Significant Mean Sten Scores for Clusters on the 16PF

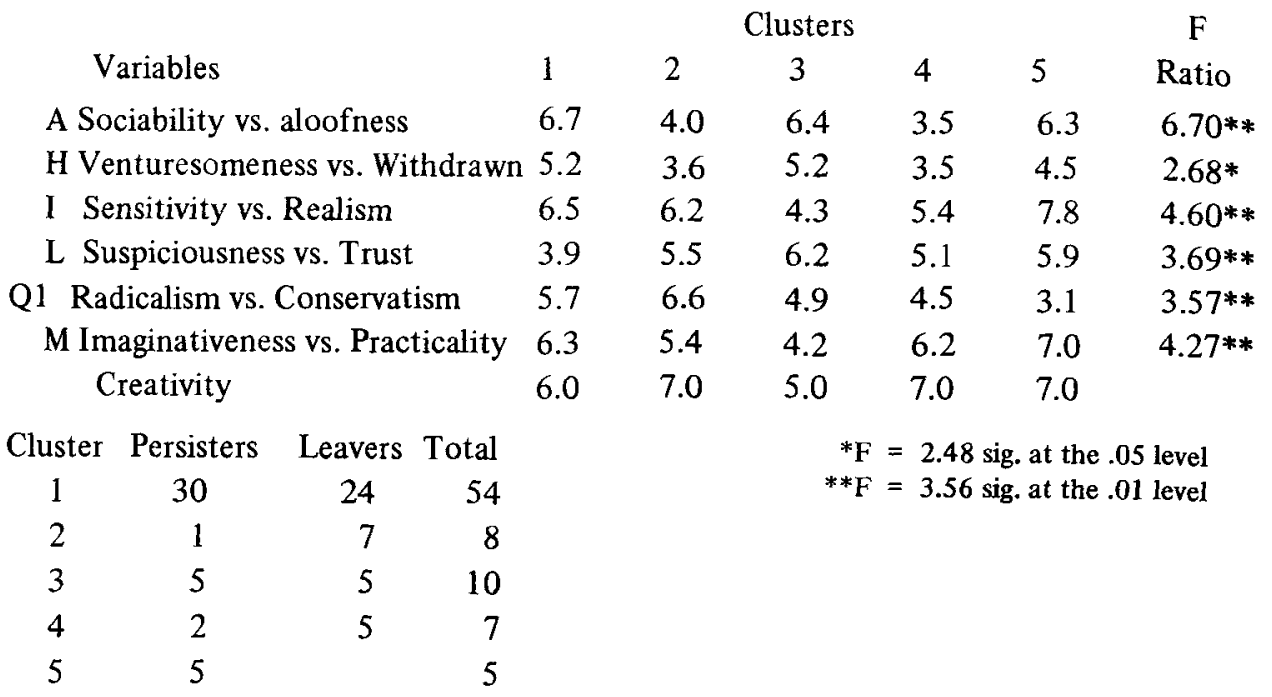

\section{TABLE V}

Significant Mean Percentile Scores for Clusters on the Kuder

\begin{tabular}{|c|c|c|c|c|c|c|c|c|c|}
\hline \multirow{2}{*}{\multicolumn{4}{|c|}{ Variables }} & \multicolumn{5}{|c|}{ Clusters } & \multirow{3}{*}{$\begin{array}{c}\mathrm{F} \\
\text { Ratio } \\
9.07^{* *}\end{array}$} \\
\hline & & & & \multirow{2}{*}{$\begin{array}{l}1 \\
24\end{array}$} & \multirow{2}{*}{$\begin{array}{l}2 \\
62\end{array}$} & \multirow{2}{*}{$\begin{array}{l}3 \\
23\end{array}$} & \multirow{2}{*}{$\begin{array}{l}4 \\
56\end{array}$} & \multirow{2}{*}{$\begin{array}{l}5 \\
29\end{array}$} & \\
\hline 0 & Outd & oor & & & & & & & \\
\hline 1 & Mect & anical & & 19 & 36 & 44 & 59 & 12 & $10.13^{* *}$ \\
\hline 2 & Com & putationa & & 47 & 25 & 72 & 84 & 31 & $4.81 * *$ \\
\hline 3 & Scier & tific & & 34 & 65 & 22 & 78 & 15 & $8.72 * *$ \\
\hline 4 & Persu & asive & & 58 & 21 & 59 & 10 & 29 & $6.84^{* *}$ \\
\hline 5 & Artis & & & 41 & 40 & 32 & 56 & 81 & $2.57 *$ \\
\hline 6 & Liter & & & 76 & 76 & 57 & 24 & 61 & $6.25 * *$ \\
\hline 7 & Musi & & & 49 & 36 & 61 & 23 & 73 & $4.35^{* *}$ \\
\hline 8 & Socia & & & 85 & 94 & 65 & 74 & 89 & $2.97^{*}$ \\
\hline 9 & Cleri & & & 51 & 23 & 81 & 57 & 70 & $5.87^{* *}$ \\
\hline Cluster & Persisters & Leavers & Total & & & ${ }^{*} \mathrm{~F}=$ & 2.48 & g. at & e. 05 level \\
\hline 1 & 30 & 24 & 54 & & & $* * \mathbf{F}=$ & & & e.01 level \\
\hline 2 & 1 & 7 & 8 & & & & & & \\
\hline 3 & 5. & 5 & 10 & & & & & & \\
\hline 4 & 2 & 5 & 7 & & & & & & \\
\hline 5 & 5 & & 5 & & & & & & \\
\hline
\end{tabular}




\section{TABLE VI}

Significant Mean Percentile Scores for Clusters on Aptitude and Achievement Tests

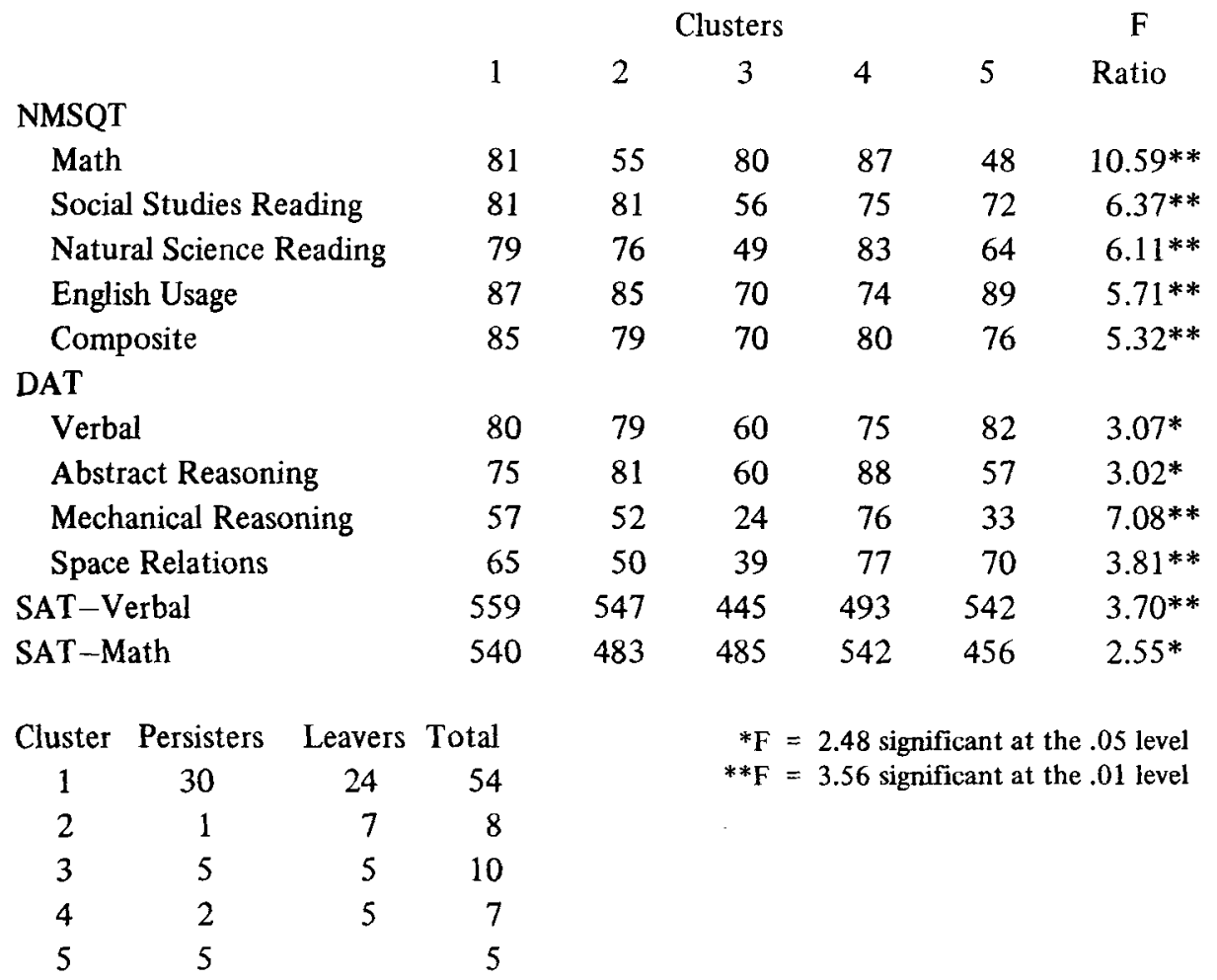

